\title{
Interplay of Collaborative Networks in Product Servicing
}

\author{
Luis M. Camarinha-Matos, Filipa Ferrada, and Ana Inês Oliveira \\ UNINOVA and FCT - Universidade Nova de Lisboa, Campus de Caparica \\ 2829-516 Monte Caparica, Portugal \\ cameuninova.pt
}

\begin{abstract}
Application contexts such as the support to service-enhanced products require the interplay of various collaborative networks along the product life-cycle. Based on the solar energy parks case, various long- and short-term networks are identified and their inter-dependencies briefly analyzed. A cloud-based collaborative environment is developed to support the various types of networks. Presented results are achieved in the context of the GloNet project.
\end{abstract}

Keywords: Collaborative networks, service-enhanced products, cloud computing.

\section{Introduction}

Most past works on Collaborative Networks have focused on a single network form, e.g. a Virtual Organization (VO). In some cases the interactions between two forms of network have been analyzed, namely the interactions between a Virtual organizations Breeding Environment (VBE) and the VOs created within that VBE [1]. Some application cases, however, require the interplay among several networks. That is the case of enterprise networks to support service-enhanced products [2].

In this case, in addition to an underlying VBE, various VOs can be foreseen namely for product manufacturing, designing the business services to enhance the product, providing multi-stakeholder composite services, etc. The reason for this need is that different stakeholders play a role at different stages of the product life-cycle. The collaborative efforts in each stage have a different purpose, and are carried out by different groups of members, although some members might be common to various networks. The life-cycles of the various networks and their duration are also different. For instance, while a service design / service co-creation VO is short-term, a service provision $\mathrm{VO}$ might have a long duration accompanying the life of the product. The service provision VO might include some members of the service design VO but in any case some inheritance mechanism between the two needs to be established.

On the other hand, in the context of a collaborative network various other formal and informal networks may emerge. Formal networks are regulated by explicit contracts or agreements. For instance, during the operation phase of a product, and thus in the context of its service provision $\mathrm{VO}$, a need for a new service might be detected, what might trigger the formation of a temporary VO for the co-creation / codesign of the new service. Informal networks, which do not involve any formal contract, emerge as "aggregations" of entities that share some common interest, often 
a case of communities of practice or social networks. These networks are often seen as the glue that holds together cross-functional process improvement initiatives or the seed for product / service co-innovation processes [3].

Understanding the interactions and dependencies among multiple collaborative networks is thus an important research challenge. This work aims at contributing to this challenge through a service-enhanced product case study conducted in the context of the GloNet project.

\section{Related Areas}

In the areas of complex networks and social networks analysis (SNA) the concept of overlapping sub-networks or communities is widely addressed. In recent years, considerable effort has been put on developing algorithms for overlapping communities' detection [4], [5], [6], [7]. The notion of community in this area, although not very well defined, typically represents a cluster or group of nodes that interact with each other more frequently than with those outside the group. As such, the aim of community detection algorithms is to identify groups of nodes more densely interconnected relatively to the rest of the network, i.e. resorting to information encoded in the graph topology.

Unfortunately, the notion of network in these areas, although conceptually attractive due to the clear mathematical properties that can be associated to the graph representation, also presents some limitations when applied to collaborative enterprise networks. For instance, the links between nodes are typically of the same kind, abstracting some form of connection (e.g. information interaction). In collaborative enterprise networks, the interactions among network members can be of very diverse types e.g. control relations, reporting relations, information flow relations, material flow relations, etc. Some approaches in SNA try to capture this diversity of relations through the notion of multiplexity, which comes from early literature in the area based on the realization that human relationships are normally multiplex or multi-stranded. It was also considered that a multiplex relation is stronger than a uniplex relation because it contains more than one basis for interaction [8], which led then to the notion of relation's strength. But such simplistic notion does not fully capture the individual semantics of the various relations and as such does not adequately support management strategies for the networks. In spite of some works on multiplex networks, the underlying mechanisms of multiplexity remain poorly understood [9]. One interesting attempt to analyze multiplexity in the context of inter-organizational networks, and particularly to understand the role of social and economic ties in the formation of dense multiplex ties is the work of Ferriani et al. [9].

The methods explored in the areas of complex networks and SNA certainly have applicability in various problem areas, namely when basic data on nodes and links exist and the purpose is to extract / discover structural properties. In the case of collaborative enterprise networks however, the "starting point" and the granularity of the analysis are usually different. The problem is not so often to identify the existence of a network / community and its members; the members are often known and the membership is established through some "contract" or agreement, which reflects some common objective. Within such collaborative group, many interactions of 
different nature might occur but they are not always known a-priori, or at least, it is not the existence of data on such interactions that lets us identify the existence of the $\mathrm{CN}$. In this sense, there are fundamental differences in the scope and approaches of the two areas.

The challenge in CNs is not to study the links/ties and their structural properties (or even how they emerge) - which are typical of a "link-oriented analysis" - but rather to progress on understanding aspects such as: Membership dependencies, time dependencies, purpose / goal dependencies, and inheritance dependencies between networks and also their supporting environments.

\section{Service-Enhanced Products Case}

The notion of service-enhanced product, also known as product-service, resulted from the need to increase product differentiation and the value of product offers. By associating business services that add value to the products, greater forms of differentiation can be achieved and new business opportunities generated since buyers of manufactured products increasingly want more than the physical product itself [10].

After decades of industrial decline, due to deliberate policies that advocated an exclusive move toward a service-oriented society, while neglecting the production of tradable goods, many countries have lost part of their industrial competitiveness in the manufacturing sector. The service-enhancement of products, and particularly the introduction of knowledge-based services, will likely help regaining competitiveness and facilitate some form of sustainable reindustrialization. Ties with end-users and local suppliers are vital in manufacturing supply chains, adding not only valuable know-how and multidisciplinary expertise while better fitting customer needs, but also increasing potential access to new markets. The agile formation of service provision networks associated to customized products and the effective involvement of the customer and local stakeholders allows for both (1) opening opportunities for manufactured goods combined with high value added services, and (2) an optimized mobilization of resources and competencies from different geographical regions. Furthermore, this approach will contribute to a transformation from a resourceintensive to a knowledge-intensive industry.

In line with this trend, GloNet, a project funded under the Factories of the Future program of the European Commission, aims at supporting complex, highly customized and service-enhanced products through collaboration with customers and local suppliers [11]. The project assumes that collaboration and co-innovation in business services, supported by Internet and cloud computing, open new perspectives of value creation in this context. GloNet started in September 2011 with a planned duration of 3 years, and involves the following organizations: CAS (Germany), UNINOVA (Portugal), University of Amsterdam (Netherlands), iPLON (Germany), SKILL (Spain), Steinbeis (Germany), KOMIX (Czech Republic), and PROLON (Denmark). The main use case in GloNet focuses on the production and life cycle support of solar energy parks [12]. The primary aim is thus to develop a solution to promote and facilitate collaboration among partner companies in this industry, while improving the process of designing, developing, monitoring and controlling solar 
plant installations. In addition to this use case, and in order to extend the applicability of GloNet results, other domains with similar abstract characteristics, such as building automation and physical incubators of enterprises, are also considered.

The effective development and life-cycle support of service-enhanced products in these domains involve the interplay of different forms of collaborative networks (Fig. 1), including long-term strategic networks and goal-oriented, short- and long-term networks, comprising a wide variety of stakeholders and roles. In summary:

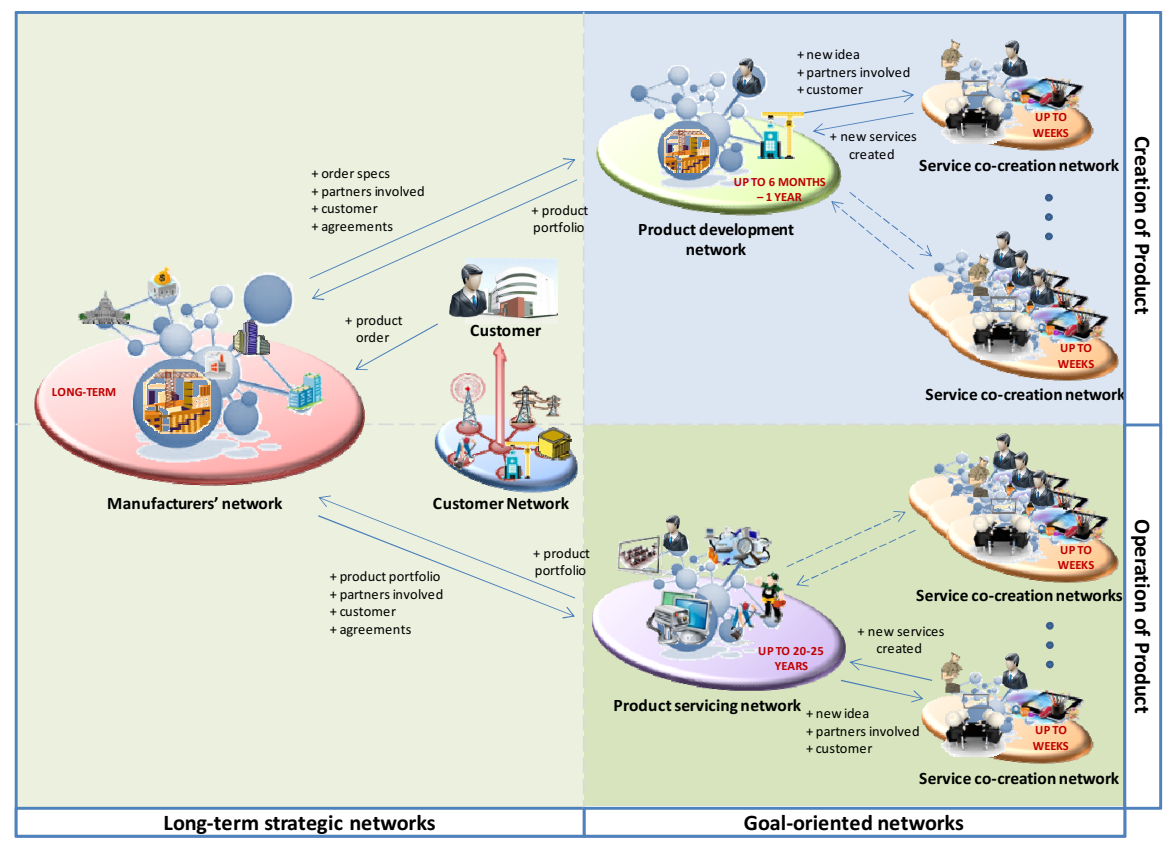

Fig. 1. Mix of collaborative networks in product development and servicing

- Manufacturers' network - a long-term alliance that typically involves product / project designers, manufacturers, service providers, and some support entities, configuring a kind of virtual organizations breeding environment (VBE) [13].

- Customer "network"- or customer related community - involving, besides the customer, local non-critical components suppliers, services providers, and a variety of support entities. Although this group might not be well organized and structured, it shares some minimal bonds like geographical vicinity, culture, business environment, legal regulations, etc.

- Product servicing network - a long-term VO organized to provide integrated or composite (multi-stakeholder) business services along the product lifecycle. In the case of the solar energy domain, an example of such network can include a monitoring and supervision company, maintenance companies, training provision entities, etc. This network needs to work in close interaction with the customer and other local stakeholders, namely regulators, utility companies, insurance companies, etc. 
- Service co-creation network - a dynamic (temporary) virtual organization (VO) involved in the design and development of new business services associated to the (physical) product. Since this area is the least developed, creation of new business services typically requires a co-innovation process carried out by a temporary consortium involving a number of participants selected from the Manufacturers network and Customer network or Product Servicing network.

Table 1 summarizes the main characteristics of these networks, based on the analysis of the solar energy parks use case.

Table 1. Summary characteristics of networks involved in service-enhanced products

\begin{tabular}{|c|c|c|}
\hline Network & Aspects & Description \\
\hline \multirow{4}{*}{$\begin{array}{l}\text { Manufacturers' } \\
\text { network }\end{array}$} & Purpose & $\begin{array}{l}\text { To jointly acquire new businesses (products and associated } \\
\text { services). }\end{array}$ \\
\hline & Membership & $\begin{array}{l}\text { In the solar parks case: Project development firms, } \\
\text { Engineering, Procurement \& Construction (EPC) companies, } \\
\text { PV equipment manufacturers, Monitoring \& Control } \\
\text { companies, Construction \& Commissioning companies. }\end{array}$ \\
\hline & Time & Long-term alliance (a kind of VBE) \\
\hline & Inheritance & $\begin{array}{l}\text { The product portfolio of this VBE will integrate the } \\
\text { outcomes of the various product development VOs and } \\
\text { service co-creation VOs. }\end{array}$ \\
\hline \multirow{4}{*}{$\begin{array}{l}\text { Customer's } \\
\text { "network" }\end{array}$} & Purpose & $\begin{array}{l}\text { As it is not a formal network, it does not have a direct goal; } \\
\text { nevertheless, the general sustainability of the associated } \\
\text { region can be seen as a common goal. }\end{array}$ \\
\hline & Membership & $\begin{array}{l}\text { In the solar parks case: Customer (owner), Utility company, } \\
\text { Lending organization, Government agencies, Insurance } \\
\text { companies, Operation \& maintenance companies, other } \\
\text { suppliers, etc. }\end{array}$ \\
\hline & Time & Long-term community \\
\hline & Inheritance & $\begin{array}{l}\text { It has access to the benefits of the product and its associated } \\
\text { services. }\end{array}$ \\
\hline \multirow{4}{*}{$\begin{array}{l}\text { Product } \\
\text { development } \\
\text { network }\end{array}$} & Purpose & To design and manufacture a new customized product. \\
\hline & Membership & $\begin{array}{l}\text { Typically includes members selected from the } \\
\text { Manufacturer's network the Customer's network. Example: } \\
\text { Project development companies, EPC, PV equipment } \\
\text { manufacturers, Construction \& Commissioning companies, } \\
\text { Monitoring \& Control companies, Lending organization, } \\
\text { Insurance company. }\end{array}$ \\
\hline & Time & Short/Medium-term VO \\
\hline & Inheritance & $\begin{array}{l}\text { The outcome of this VO will be inherited by the product- } \\
\text { servicing VO and will become part of the product portfolio } \\
\text { of the manufacturers VBE. }\end{array}$ \\
\hline \multirow{4}{*}{$\begin{array}{l}\text { Product } \\
\text { servicing } \\
\text { network }\end{array}$} & Purpose & $\begin{array}{l}\text { To provide integrated (multi-stakeholder based) business } \\
\text { services along the life of the product. }\end{array}$ \\
\hline & Membership & $\begin{array}{l}\text { Example: Operation \& maintenance companies, Monitoring } \\
\text { \& Control companies, Utility company, etc. }\end{array}$ \\
\hline & Time & Long-term $\mathrm{VO}$ \\
\hline & Inheritance & $\begin{array}{l}\text { It has access to the results of both the product development } \\
\text { VO and service co-creation VO. }\end{array}$ \\
\hline
\end{tabular}


Table 1. (continued)

\begin{tabular}{|l|l|l|}
\hline \multirow{4}{*}{$\begin{array}{l}\text { Service co- } \\
\text { creation } \\
\text { network }\end{array}$} & Purpose & $\begin{array}{l}\text { To design a new service for the product, following a co- } \\
\text { creation process. }\end{array}$ \\
\cline { 2 - 3 } & Membership & $\begin{array}{l}\text { It might include members from the product development } \\
\text { network or from the product servicing network (depending } \\
\text { on the time of launching), combined with some elements } \\
\text { from the customer's network, including the customer. }\end{array}$ \\
\cline { 2 - 3 } & $\begin{array}{l}\text { Thort-term VO. Different service co-creation networks can } \\
\text { be launched during the operation phase of either the product } \\
\text { development VO or the product servicing VO, according to } \\
\text { identified needs for new services. }\end{array}$ \\
\cline { 2 - 3 } & Inheritance & $\begin{array}{l}\text { The outcome of this VO (the service design) will be } \\
\text { inherited by the service provision VO. In case the service is } \\
\text { generic enough to be exploitable in other products, it is also } \\
\text { inherited by the manufacturers' VBE. }\end{array}$ \\
\hline
\end{tabular}

\section{Support Environment}

In order to support the life-cycle and interplay of the various collaborative networks involved in service-enhanced products, an ICT support environment is developed in GloNet according to the general architecture illustrated in Fig. 2.

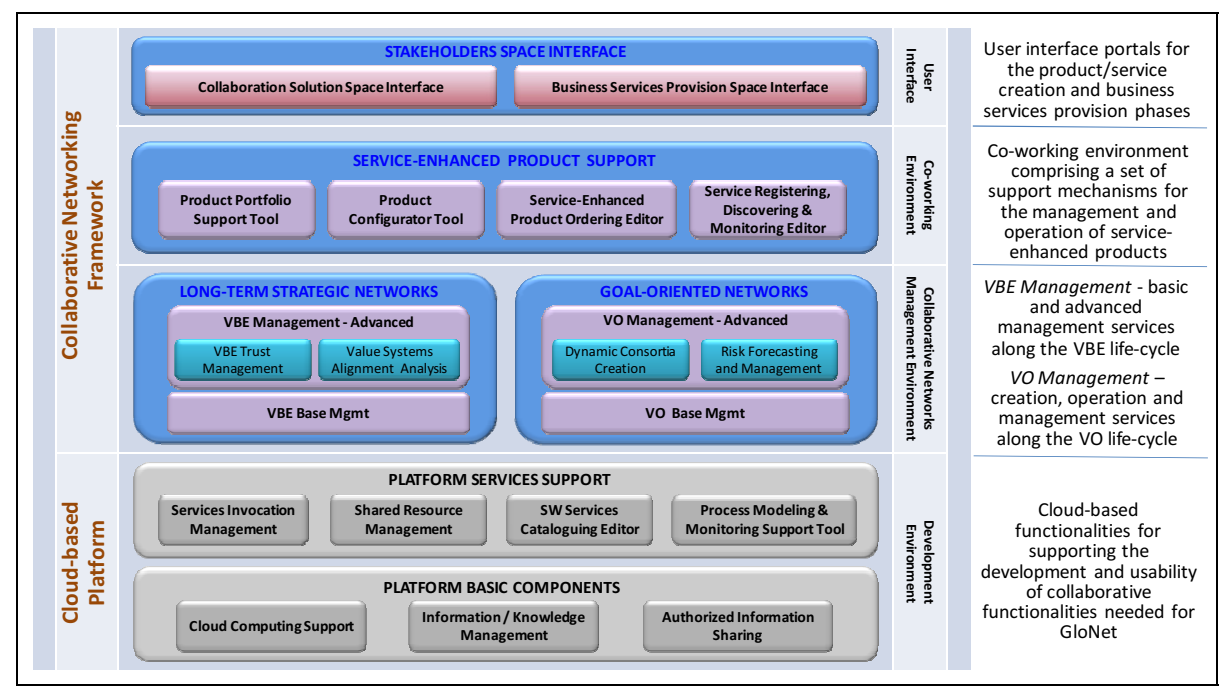

Fig. 2. GloNet system architecture

This system consists of two high-level modules, namely:

- Cloud-based Platform - which aims at providing the enabling cloud services for giving support to the development and usability of collaborative functionalities needed for GloNet. 
- Collaborative Networking Framework - which aims at providing functionalities needed for collaboration spaces and to support the different forms of collaborative networks, comprising a wide variety of stakeholders that get together in order to create service-enhanced products.

These two high-level modules of the architecture are then divided into a set of layers.

One of the main components of the CN Framework is the VBE management subsystem, whose functionalities, inspired on ECOLEAD [14], are illustrated in Fig. 3.

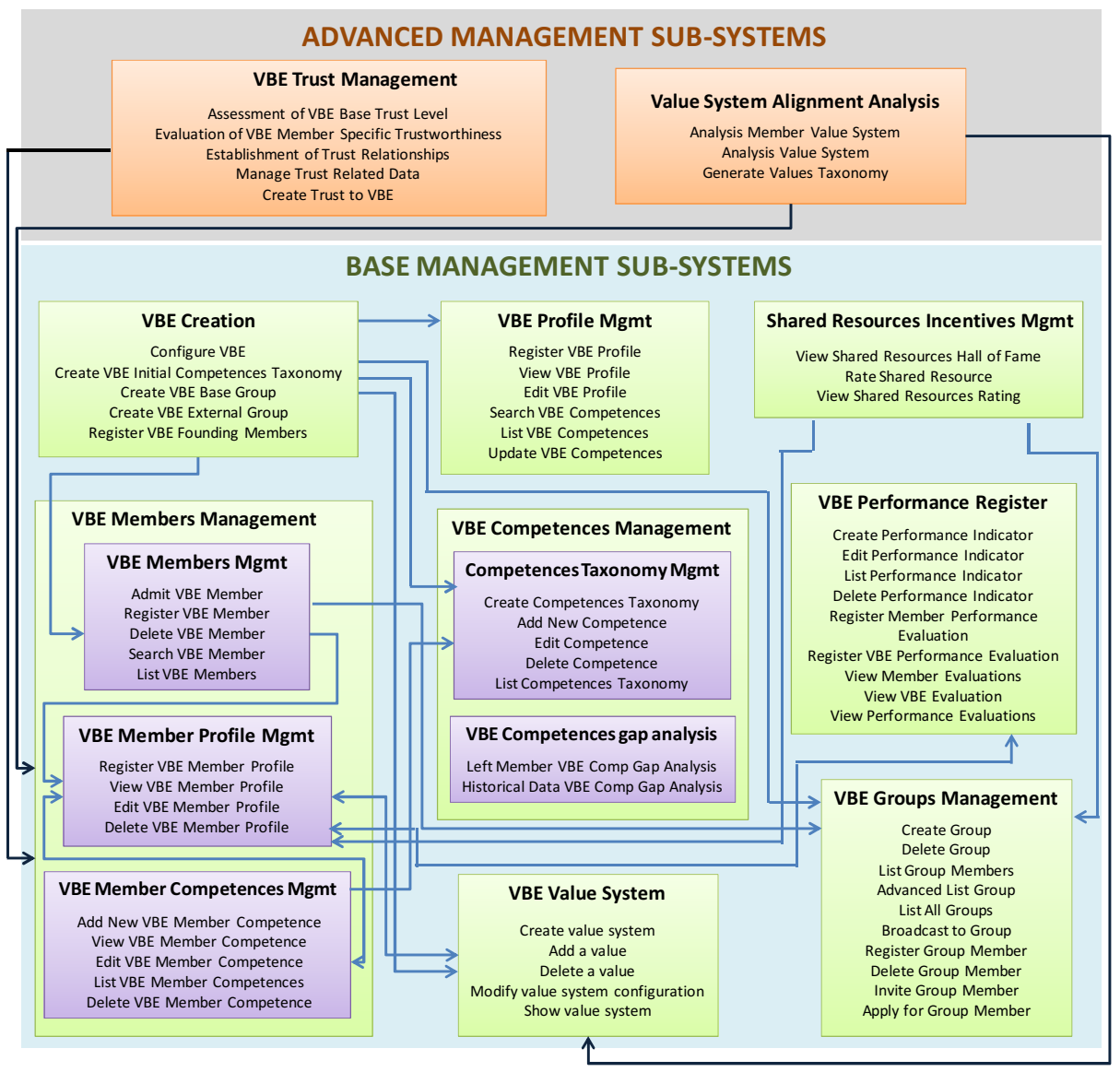

Fig. 3. VBE Management functionalities

Another important component is the VO management system, to support the various goal-oriented networks. As an example of the modules included in this component, the functionalities to support the VO creation are illustrated in Fig. 4. 


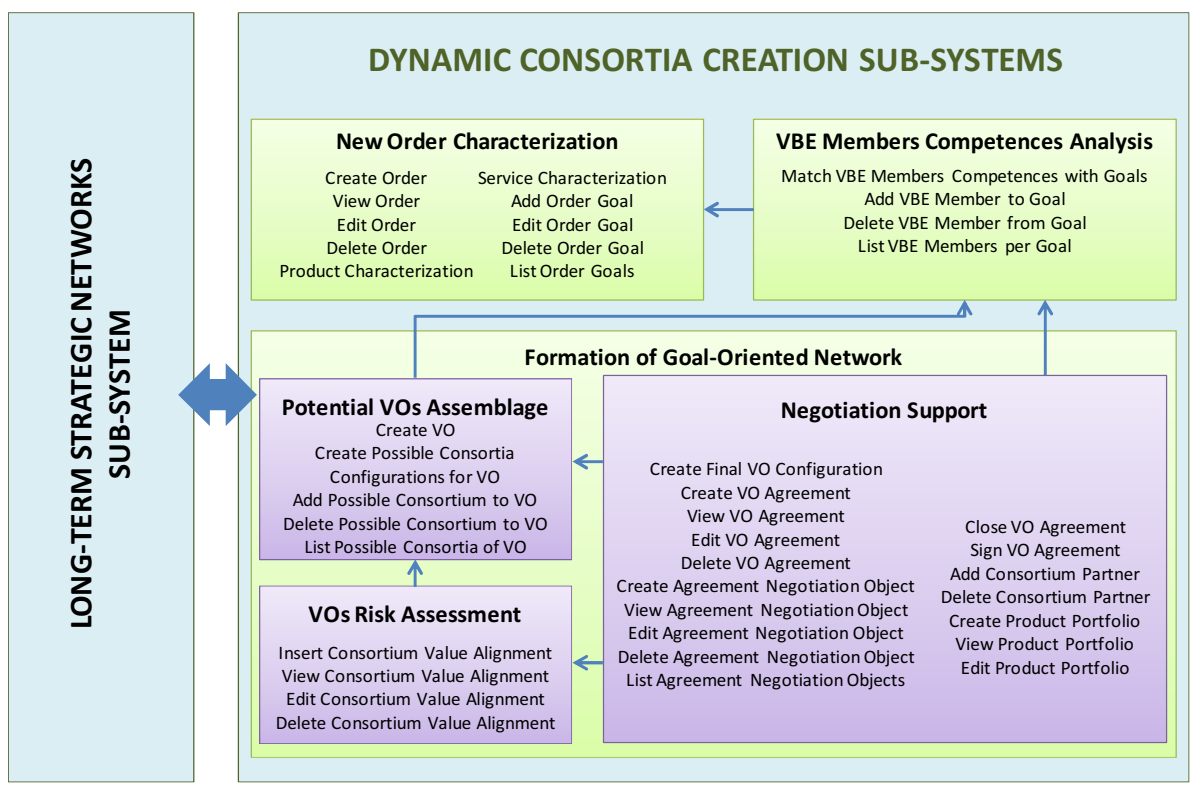

Fig. 4. VO Creation functionalities

On top of these components, GloNet introduces a co-working environment that comprises a set of support mechanisms for the management and operation of serviceenhanced products, including product and service configuration, product portfolio management, user interfaces, etc.

At the user interface layer there are two portals: the Collaboration Solution Space Interface that aims at providing an access point through which manufacturers, local suppliers and customers "meet" to co-create the product and its associated services; and the Business Services Provision Space Interface that aims at providing an access point to the "registry" of the products along their life-cycle through which customers can have access to the specific services associated to the customized product.

The GloNet system is developed on top of a cloud-based platform. Besides the initial lower cost in setting up the cloud's hardware as compared to conventional physical local setups at every company, factors such as ease of servicing, upgrading and maintaining suggest a cloud-based infrastructure as a promising environment for this context. There are, however, various aspects to be better assessed, e.g. vendor lock-in, integration of components running in different infrastructures, and the associated business models.

Considering the above support functionalities, Fig. 5 illustrates the process of selecting partners for a VO creation. In this example, potential partners are selected from both the VBE (e.g. Manufacturer's network) and the Customer's "network" (indicated as External Interested Stakeholders in the diagram). 


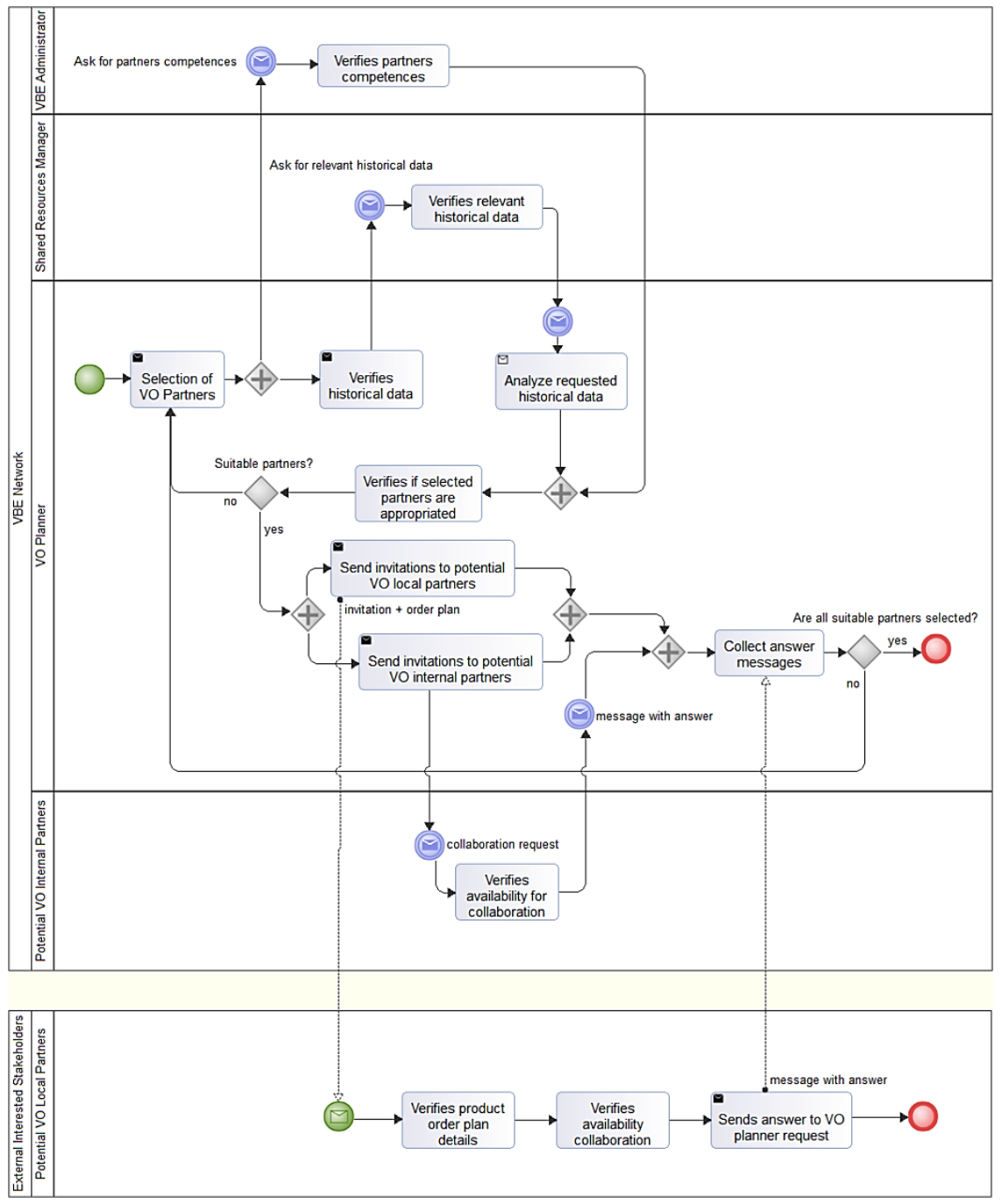

Fig. 5. BPMN diagram for the selection of goal-oriented VO partners

\section{Conclusions}

The concepts and mechanisms originated in the $\mathrm{CN}$ area are nowadays penetrating many application domains. Furthermore, in various use cases we can identify a mix of long- and short-term networks, strategic and goal-oriented networks, and formal and informal networks. The coexistence and interactions among these multiple networks, often with overlapping structures and membership, raises new research challenges.

As a contribution to better understand the interplay among diverse CNs, and to support their life-cycles, GloNet project is focusing on the needs of service-enhanced products and their associated servicing networks. The proposed collaboration 
environment was designed to also cope with the needs of involving local stakeholders, close to the customer, in the process of co-creation of new services. The actual validation of the proposed solutions in the context of solar energy parks is an ongoing work.

Acknowledgments. This work was funded in part by the European Commission through the GloNet project (FP7 programme). The authors also thank the contributions from their partners in this project.

\section{References}

1. Camarinha-Matos, L.M., Oliveira, A.I., Sesana, M., Galeano, N., Demsar, D., Baldo, F., Jarimo, T.: A framework for computer-assisted creation of dynamic virtual organizations. International Journal of Production Research 47(17), 4661-4690 (2009)

2. Camarinha-Matos, L.M., Macedo, P., Ferrada, F., Oliveira, A.I.: Collaborative Business Scenarios in a Service-Enhanced Products Ecosystem. In: Camarinha-Matos, L.M., Xu, L., Afsarmanesh, H. (eds.) PRO-VE 2012. IFIP AICT, vol. 380, pp. 13-25. Springer, Heidelberg (2012)

3. Cross, R., Nohria, N., Parker, A.: Six Myths About Informal Networks - and How To Overcome Them. In: MIT Sloan Management Review. Spring (2002)

4. Xie, J., Kelley, S., Szymanski, B.K.: Overlapping Community Detection in Networks: the State of the Art and Comparative Study. ACM Computing Surveys 45(4) (2013)

5. Chen, D., Shang, M., Lv, Z., Fu, Y.: Detecting overlapping communities of weighted networks via a local algorithm. Physica A: Statistical Mechanics and its Applications 389(19), 4177-4187 (2010)

6. Rees, B.S., Gallagher, K.B.: Overlapping Community Detection by Collective Friendship Group Inference. In: Proceedings of 2010 International Conference on Advances in Social Networks Analysis and Mining, August 9-11, pp. 375-379. IEEE, Odense (2010)

7. Orman, G.K., Labatut, V., Cherifi, H.: Qualitative comparison of community detection algorithms. In: Cherifi, H., Zain, J.M., El-Qawasmeh, E. (eds.) DICTAP 2011 Part II. CCIS, vol. 167, pp. 265-279. Springer, Heidelberg (2011)

8. Skvoretz, J., Agneessens, F.: Reciprocity, Multiplexity, and Exchange: Measures. Quality \& Quantity 41, 341-357 (2007)

9. Ferriani, S., Fonti, F., Corrado, R.: The social and economic bases of network multiplexity: Exploring the emergence of multiplex ties. Strategic Organization 11(1), 7-34 (2013)

10. Shen, Q.: Research on Organization Mode Selection of Service-enhanced Manufacturing Enterprise. In: Proc.s 3rd Int. Conf. Information Management, Innovation Management \& Industrial Engineering, November 26-28, pp. 358-361. IEEE, Kunming (2010)

11. Camarinha-Matos, L.M., Afsarmanesh, H., Koelmel, B.: Collaborative Networks in Support of Service-Enhanced Products. In: Camarinha-Matos, L.M., Pereira-Klen, A., Afsarmanesh, H. (eds.) PRO-VE 2011. IFIP AICT, vol. 362, pp. 95-104. Springer, Heidelberg (2011)

12. Afsarmanesh, H., Thamburaj, V.: ICT Requirements Analysis for Enterprise Networks Supporting Solar Power Plants. In: Camarinha-Matos, L.M., Xu, L., Afsarmanesh, H. (eds.) PRO-VE 2012. IFIP AICT, vol. 380, pp. 149-157. Springer, Heidelberg (2012)

13. Camarinha-Matos, L.M., Afsarmanesh, H.: On reference models for collaborative networked organizations. Int. J. Production Research 46(9), 2453-2469 (2008)

14. Camarinha-Matos, L.M., Afsarmanesh, H., Ollus, M.: Methods and tools for Collaborative Networked Organizations. Springer, New York (2008) 